\title{
Falando de Morte e da Finitude no Ambiente Escolar: Um Estudo à Luz do Sentido da Vida
}

\author{
Speaking of Death and Finiteness in a School \\ Environment: A Study in Light of the Meaning of Life \\ Hablando de Muerte y de la Finitud en el Ambiente \\ Escolar: Un Estudio a la Luz Del Sentido de la Vida
}
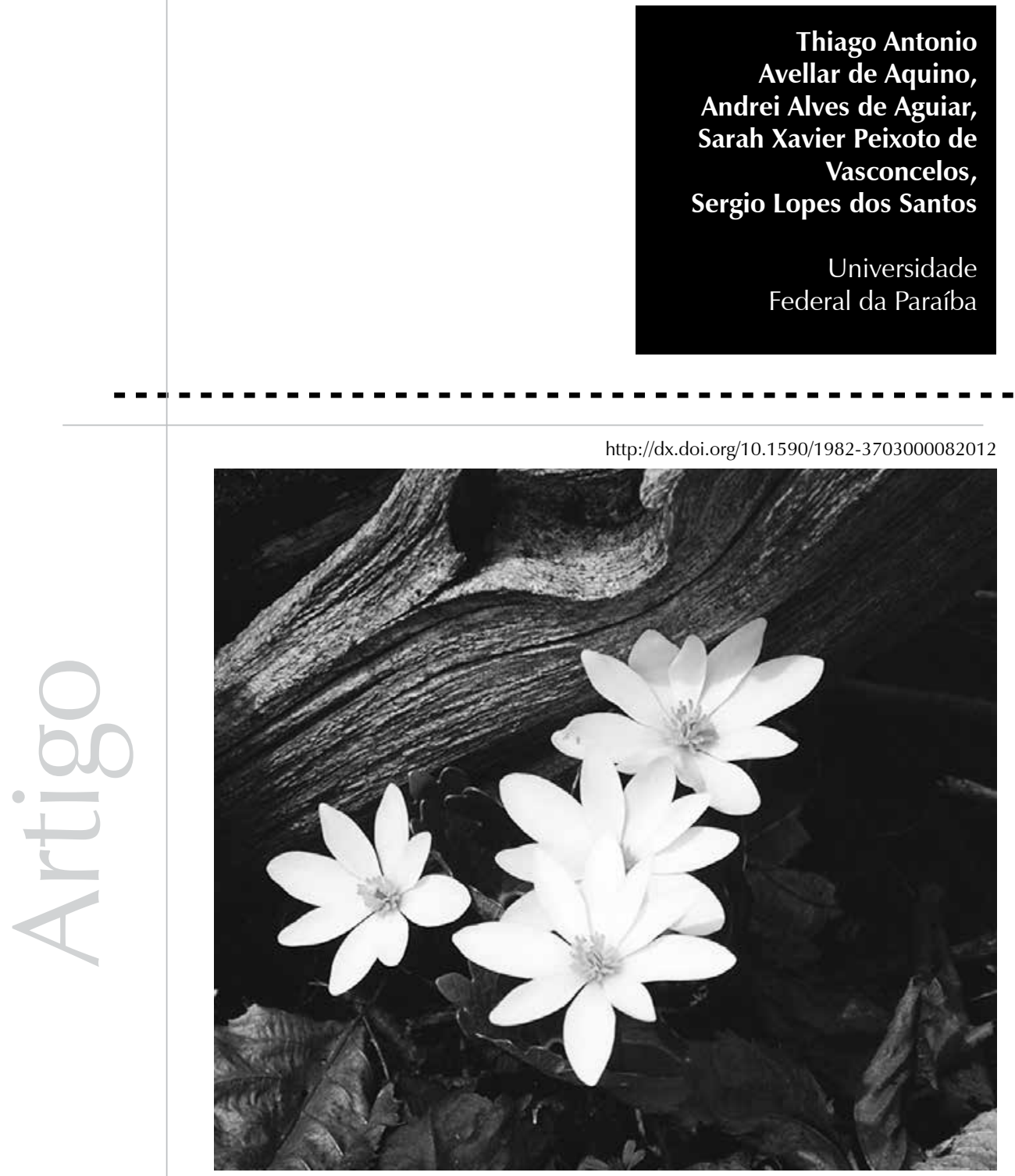
Resumo: O presente estudo teve como objetivo identificar as concepções da morte e suas repercussões para o sentido da vida entre os adolescentes. Para tanto, foi efetuada uma pesquisa-ação para abordar o tema da finitude partindo da concepção de Viktor Frankl sobre o sentido da vida e da morte. Contou-se com a participação de 17 estudantes do terceiro ano do ensino médio, a maioria do sexo feminino (52,9\%), com idade média de 17 anos e amplitude de 15 a 24 anos. Os resultados foram obtidos por meio de cinco intervenções em sala de aula. Cada intervenção teve a duração média de 45 minutos, constituindo-se de questionamentos acerca da morte, do morrer e do sentido da vida. Em seguida, as respostas dos participantes foram submetidas a uma análise de conteúdo. No que se refere às representações da morte, emergiram três categorias: pensamentos, sentimentos e crenças. Sobre a compreensão do sentido da vida, os adolescentes responderam em duas direções: os sentidos subjetivos e sentidos objetivos. Quando refletiram sobre a própria morte, as suas respostas foram classificadas em termos de três categorias valorativas: vivenciais, atitudinais e criativos. No que se refere à pergunta "Como seria a vida se ninguém morresse?", foram observados os seguintes tipos de argumentos: valorização da vida, corrigir erros do passado, resposta tautológica, resposta religiosa e dialética vida-morte. Os resultados mostraram a importância de tratar sobre o tema da finitude no âmbito escolar.

Palavras-chave: Morte. Adolescentes. Atitudes frente à morte. Educação em relação à morte.

Abstract: The present study aimed to identify the conceptions of death and its implications for the meaning of life among adolescents. To that end, we performed an action-research to address the issue of finiteness starting from the Viktor Frankl conception about the meaning of life and death. We counted with the participation of 17 third year students in high school, the majority of them females (52.9\%) with mean age 17 years, ranging from 15 to 24 years old. The results were obtained through five interventions in the classroom. Each intervention lasted on average 45 minutes, being constituted by the questions about death, dying and the meaning of life. Then, the participants' responses were subjected to content analysis. With respect to representations of death, three categories were revealed: thoughts, feelings and beliefs. About the understanding the meaning of life, the adolescents responded in two directions: the subjective and objective senses. When reflected on their own death, their answers were classified in terms of three evaluative categories: experiential, attitudinal and creative. With regard to the question "How would life be if nobody died", the following types of arguments were observed: valuing life, correcting past mistakes, tautological answer, religious response and life-death dialectic. The results showed the importance of dealing with the subject of finitude in schools.

Keywords: Death. Adolescent. Attitudes towards death. Death education.

Resumen: El presente estudio tuvo como objetivo identificar las concepciones de la muerte y sus repercusiones para el sentido de la vida entre los adolescentes. Para tanto, fue efectuada una pesquisaacción para abordar el tema de la finitud partiendo de la concepción de Viktor Frankl sobre el sentido de la vida y de la muerte. Se contó con la participación de 17 estudiantes de tercer año de enseñanza media, la mayoría del sexo femenino (52,9\%), con edad media de 17 años y amplitud de 15 a 24 años. Los resultados fueron obtenidos por medio de cinco intervenciones en clase. Cada intervención tuvo la duración media de 45 minutos, siendo constituida de cuestionamientos acerca de la muerte, del hecho de morir y del sentido de la vida. A continuación, las respuestas de los participantes fueron sometidas a un análisis de contenido. En lo que se refiere a las representaciones de la muerte, emergieron tres categorías: pensamientos, sentimientos y creencias. Sobre la comprensión del sentido de la vida, los adolescentes respondieron en dos direcciones: los sentidos subjetivos y sentidos objetivos. Cuando reflexionaron sobre la propia muerte, sus respuestas fueron clasificadas en términos de tres categorías valorativas: vivenciales, actitudinales y creativas. En lo que se refiere a la pregunta "¿Cómo sería la vida si nadie muriese?", fueron observados los siguientes tipos de argumentos: valorización de la vida, corregir errores del pasado, respuesta tautológica, respuesta religiosa y dialéctica vida-muerte. Los resultados mostraron la importancia de tratar sobre el tema de la finitud en el ámbito escolar.

Palabras clave: Muerte. Adolescentes. Actitudes frente a la muerte. Educación con relación a la muerte.

Segundo Ariés (1977), o tema da morte torna-se um tabu no século XX e, por isso, autores como Kovács (2005) têm apresentado preocupações acerca da ausência de uma espécie de educação para a morte nos contextos escolares. Segundo essa mesma autora: a educaçãoéentendida como desenvolvimento pessoal, aperfeiçoamento e cultivo do ser, que também pressupõe uma preparação para a morte, envolvendo comunicação, relacionamentos, perdas, situações-limites, como, por exemplo: fase do desenvolvimento, perda de pessoas significativas, doenças, 
Embora a morte faça parte do cotidiano dos estudantes, a escola não contempla em seu currículo essa temática. acidentes, até o confronto com a própria morte (Kovács, 2005, p. 485).

Embora a morte faça parte do cotidiano dos estudantes, a escola não contempla em seu currículo essa temática. Patraglia e Bastos (2009) justificam a inclusão desse tema nas escolas, posto que seja, presumivelmente, um fator educativo do espírito que proporciona ao educando uma consciência de si. Ademais, em contextos universitários, é possível observar que as visões acerca da morte estão associadas ao sentido da vida de tais sujeitos (Aquino et al., 2010). Outra variável relevante que está relacionada com as visões de morte é a religiosidade. O estudo de Diniz e Aquino (2009) sugere que as visões de morte como: vida do além, coragem e fim natural associam-se positivamente com a atitude religiosa, enquanto que a morte como fracasso se comporta de maneira inversa. Com a inclusão do ensino religioso nas escolas públicas, o tema da morte pode ser tratado de uma forma transdisciplinar. Não obstante, torna-se imperativo conhecer como os aprendizes representam a morte e quais as suas possíveis repercussões para a compreensão do sentido da vida.

\section{A morte e suas repercussões psicológicas}

A morte é um fenômeno que faz parte da vida, pois se constitui como algo inerente à própria existência. Embora se constitua como um ser-para-morte, Sein zum Tode (Heidegger, 1989), o ser humano apresenta diversas atitudes e percepções sobre a morte. Tais atitudes e percepções sofreram grandes mudanças ao longo dos séculos e, por conseguinte, modificaram a concepção da vida dos indivíduos (Ariès, 1977). Segundo Kovács (1992), é por via da tradição cultural que os indivíduos adquirem concepções sobre a morte, e o morrer, na sociedade ocidental, é um ponto central da existência humana, que geralmente está associado à tristeza e ao sofrimento.

Historicamente, a morte foi percebida de diversas maneiras: na Idade Média, por exemplo, a morte era algo natural e esperado, possibilitando ao homem a oportunidade de morrer em seu leito, confortado por familiares e amigos. Conforme Ariès (1977), nos séculos $\mathrm{V}$ e $\mathrm{VI}$, a morte era concebida como um fenômeno integrado à vida cotidiana do ser humano, pois era percebida com pouca dramaticidade e com naturalidade. Nessa perspectiva, os entes queridos ficavam em volta do caixão por vários dias, para proporcionar uma despedida ao defunto. Destarte, no período medieval, a morte era um fenômeno doméstico. O moribundo preparava-se para morrer e administrava a própria morte, ela não representava uma ruptura definitiva com relação à vida. Concluise que os medievais viam a morte como a passagem para uma vida eterna, o que transmitia um sentimento de conforto. Nesse sentido, a morte era percebida apenas como uma separação temporária entre os familiares, pois representava uma continuidade entre vivos e mortos (Ariès, 1977).

Ainda na Idade Média surgem dúvidas sobre a vida pós-morte, sobre a ressurreição e a vida eterna, fazendo com que os indivíduos comecem a temer pela morte e a ter um apego pela vida. Com o tempo, as representações acerca do morrer foram se modificando, sobretudo com o advento da burguesia, quando a morte passa a ser exaltada e dramatizada, surgindo as cenas do choro e cerimoniais de luto (Ariès, 1977).

Para Schopenhauer (2000), a morte constituise como a musa inspiradora da filosofia. Segundo ele, com o advento da razão, surge de forma concomitante o medo da morte. Se o conhecimento da morte, por um lado, gera angústia, por outro, a razão filosófica e religiosa apresentam concepções metafísicas 
consoladoras. Ademais, o temor humano da morte constitui-se no pensamento do não ser, decorrente da consciência da finitude; entretanto a morte não seria diferente do momento anterior ao nascimento, quando o ser humano ainda não existia. Dessa forma, explica o autor que não há nenhuma diferença no que se refere ao antes do nascimento e o pós-morte, apenas que ambos são mediados por "um sonho efêmero de vida" (Schopenhauer, 2000, p. 67).

A morte, segundo Heidegger (1990), seria a "possibilidade da impossibilidade absoluta de pré-sença" (p. 32), por esse motivo se caracteriza como uma possibilidade irremissível e insuperável. Seria uma certeza empírica, afinal, o ser humano sabe que irá morrer, mas não sabe quando; assim sendo, o se constitui como angústia. Destarte, o autor em foco considera que "é na disposição da angústia que o estar-lançado na morte se desentranha para a pré-sença de modo mais originário e penetrante" (Heidegger, 1990, p. 33).

Autores como Spilka, Stout, Milton e Sizemore (1977) sugerem que os estudos sobre as visões de morte levem em conta suas diversas dimensões, indicando oito aspectos para se compreender as diversas concepções da morte:

1. Dor e solidão: representa a morte como um momento de agonia, isolamento, miséria, angústia e solidão.

2. Vida do além: concebe a morte como uma nova vida, plena de satisfação, felicidade, recompensa e união com Deus.

3. Indiferença: sugere a morte como um algo indiferente para o ser humano.

4. Desconhecida: apresenta a perspectiva da morte como incerteza, mistério e desconhecimento.

5. Abandono: imagina a morte como o abandono de entes queridos e como um momento para se sentir culpado.
6. Coragem: concebe a morte como uma oportunidade para demonstrar virtudes, no caso, enfrentar o último teste da vida.

7. Fracasso: indica a morte como algo que impede a realização do potencial pessoal, por exemplo, a realização de objetivos e sentido da vida.

8. Fim natural: a morte é concebida apenas como a conclusão natural da vida.

Um estudo realizado por Nogueira e Pereira (2006) investigou como a religiosidade pode influenciar nas perspectivas de morte. Os autores concluíram que tanto os católicos como os agnósticos são os grupos que apresentam mais dúvidas a respeito da morte e que quanto maior o nível de religiosidade menor a perspectiva da morte como fracasso e maior como coragem.

O medo e a ansiedade da morte podem ser agravados quando o ser humano é acometido por questões existenciais, como pode ser demonstrado na pesquisa de Donovan (1993), que constatou que quanto maior é o vazio existencial maior o nível de ansiedade perante a morte. Spilka et al. (1977) sugerem que as correlações positivas entre morte e ansiedade decorrem da ênfase que a sociedade dá ao individualismo. Para Xausa (2003), o homem atual se destitui de toda concepção religiosa sobre a morte para resolução do confronto com a finitude, mas esta ainda provoca angústia no ser humano.

Kovács (1992), por sua vez, aventa que a morte estaria associada ao medo de morrer, do sofrer e da impotência; do receio do que vem após a morte, do julgamento divino e da perda das relações com os outros; medo da extinção, medo do desconhecido. A morte também pode evocar a pergunta pelo sentido da vida (Frankl, 1990), gerando uma ansiedade existencial que levaria o ser humano a uma busca de significado para a existência. 


\section{Análise existencial do sentido da vida}

A cidade de Viena foi testemunha da constituição de três escolas de psicoterapia, a psicanálise (Sigmund Freud, 1856-1939), a Psicologia individual (Alfred Adler, 18701937) e a logoterapia (Viktor Frankl, 19051997), que interpretaram o ser humano em três perspectivas distintas. Respectivamente, essas abordagens descobriram no ser humano uma vontade de prazer, de poder e de sentido. Esses motivadores são descritos a seguir:

Motivador Prazer: trata-se da concepção hedonista que apregoa o princípio de que todo ser vivo se aproxima das experiências prazerosas e se distancia das experiências de dor. Essa concepção encontra-se na filosofia de Epicuro (342 a. C.), o prazer como um bem supremo. Nesse sentido, a verdadeira felicidade é encontrada por meio da ausência do sofrimento, ou seja, na ausência da dor e na imperturbabilidade da alma. O prazer também estaria relacionado com os instintos, o que Freud (1933/1976) denominou de Trieb (pulsão), sendo a sua origem atribuída ao estado de excitação do corpo, sendo a sua finalidade a eliminação dessa excitação. Conclui esse autor que a modificação corporal, em última instância, é sentida como satisfação. De forma geral, a partir de seus estudos com as histéricas de Viena, Freud concebeu o ser humano como um ser regido por conflitos intrapsíquicos inconciliáveis entre o ld, o Ego e o Superego.

Motivador Poder: concebe a vontade de potência (Nietzsche, 1996) como um princípio orientador da existência. Para esse autor, a natureza do ser é constituída a partir do esforço para exercer maiores quantidades de poder. Adler (1931/1998) via o ser humano em relação ao meio social e derivou daí a sua vontade de superioridade.
Essa luta pelo poder pode ser mais bem compreendida como uma derivação de uma inferioridade orgânica emergindo em situações que requerem a superação de complexos de inferioridade.

Motivador Sentido: de acordo com Frankl a vontade de sentido seria “(...) simplesmente aquilo que é frustrado no homem sempre que ele é tomado pelo sentimento de falta de sentido e de vazio" (Frankl, 1991, p. 25). Trata-se, portanto, de uma motivação primária, tendo em vista que não seria uma derivação de outro fenômeno, como um subproduto; dessa forma, constitui-se como uma motivação genuinamente humana.

Diferentemente de Freud e de Adler, a logoterapia definiu o ser humano como um ser que almeja, em ultima instância, constituir uma existência plena de sentido. Suas investigações clínicas e filosóficas concluíram que se a pessoa for frustrada na sua motivação primária, ou seja, na busca de sentido, esta poderá perder o seu principal fator de proteção do psicofísico, tornando-se suscetível ao adoecimento e aos transtornos psicossociais como agressão, drogadição e suicídio (Frankl, 1990).

Segundo Frankl (1989), os motivadores prazer e poder são ativados de forma exagerada quando o sentido se encontra em um nível crítico ou baixo. Em outras palavras, quando há uma frustração na busca de sentido, há, por conseguinte, uma elevação da busca de prazer e do poder. Essa frustração pode ocorrer em algumas circunstâncias, sobretudo quando o passado é carente de sentido e o futuro não é percebido com possibilidades de realização de valores. Outra circunstância seria quando o presente é percebido como sem nenhuma possibilidade de sentido, ocasionando um vazio existencial. Em todo caso, há uma carência de valores, seja no 
passado ou no presente, e uma restrição da percepção de valores no futuro.

O modelo teórico em questão parte da premissa de que a preocupação com os valores surge com a consciência da finitude. Assim, esses mesmos valores servem como guias para escolhas e opções durante a vida. Também parte da premissa de que os valores são constituídos a partir da sua realização, já que o homem se encontra em uma tensão entre o ser e o dever-ser. Dessa maneira, a essência da pessoa humana é realizada na medida em que efetua atos valorativos. Para Frankl (1989), os valores se constituem como o "marca-passo" da existência, visto que, ao ser concretizado, faz parte do ser passado, estabelecendo-se como a dimensão mais segura do ser humano, já que se cristaliza de forma indelével no seu projeto existencial.

Segundo Mondin (2005), "mais que um fato realizado, o homem é uma reserva de possibilidades. Ele é um projeto aberto, inteiramente a se definir e realizar" (p.53). Segundo ele, o papel da axiologia é o de esclarecer quais valores são essenciais para realizar o projeto de humanidade. Segundo Frankl (1989), os valores são vias para realização de sentido. Esse mesmo autor concebe três categorias valorativas pelas quais o homem comum, em sua compreensão ontológica, encontra sentidos. São elas: valores criativos, vivenciais e atitudinais.

Valor criativo: relaciona-se com os atos criativos, tais como a constituição de obras artísticas e científicas, e está associado à capacidade de produção do ser humano, ou seja, ao trabalho.

Valor vivencial: enquanto no valor criativo o ser humano constrói algo para o mundo, no valor vivencial, ele recebe alguma coisa do mundo em forma de vivências. Esse valor abarca tanto a contemplação artística ou a própria natureza, quanto o encontro com outro ser humano no binômio eu-tu. Este último está relacionado à experiência do amor.

Valor atitudinal: esse último valor está relacionado à capacidade do ser humano de se posicionar perante uma situação imutável, em geral, o sofrimento. Quando a pessoa humana não possui mais a sua capacidade de produzir e está privada dos valores de vivência, ela ainda possui a liberdade de se posicionar, proporcionando-lhe uma realização interior de sentido.

Na relação do homem com os valores, observa-se o fenômeno antropológico da autotrancendência da existência, isto é, a pessoa humana deveria estar voltada para algo ou alguém que não o próprio eu. Portanto, aqueles que, de forma excessiva, voltamse para si, não se abrem para o mundo, podem estar indicando uma espécie de neurose, constituindo-se, assim, um indício de neurose aqueles que se voltam para si mesmos de forma excessiva (Frankl, 1991). Nessa direção, o poder e o prazer não se constituiriam como fins em si mesmos, mas consequências da realização existencial de sentidos. Assim, o prazer e o poder não seriam valores finais, posto que não são objetos de intencionalidade. Ademais, na sociedade pósindustrial, observa-se que o projeto do "ter" se sobrepõe ao projeto do "ser", escamoteando os debates sobre a morte, pois estes não estariam reforçando os valores materialistas dos sistemas das sociedades de consumo e de produção.

\section{Antropologia filosófica da logoterapia}

Os pressupostos básicos da logoterapia e análise existencial acerca dos valores podem ser resumidos da seguinte forma:

- Os valores são motivadores da existência humana. Esse pressuposto está fundamentado 
na perspectiva teleológica, a qual concebe que o ser humano se move pelos fins. Assim, o ser humano seria atraído pelos valores; - Os valores são objetos de intencionalidade, pressuposto husserliano que reza que toda consciência é consciência de algo;

- Por conseguinte, os valores não são apenas subjetivos, mas se constituem como autênticas possibilidades de ser-no-mundo; - A preocupação com valores decorre da consciência da finitude. Em outras palavras, o ser humano preocupa-se com a realização de valores porque sabe que um dia irá morrer, surgindo o desejo/vontade de conferir à vida um significado;

- A preocupação com os valores é derivada da dimensão noética e se apresenta de forma hierárquica nas situações em que o ser humano está inserido; os valores que são mais dignos de realização são aqueles que conferem mais sentido à vida e dignifica a humanidade, ou seja, exerce uma influência positiva para si mesmo, para outras pessoas e para o mundo.

A concepção dos valores está relacionada ao conceito da ontologia dimensional. Frankl (1989) distingue três partes interrelacionadas, quais sejam: a noética, a psíquica e a somática. Embora possam ser definidas de formas distintas, elas se constituem em uma unidade indissolúvel constituindo em uma imagem do ser humano tridimensional (Frankl, 1989). A dimensão somática constitui-se dos aspectos fisiológicos e biológicos do ser humano e dos animais e dos vegetais; já a dimensão psíquica corresponde aos afetos e a todos os processos básicos, como percepção, aprendizagem, sensação, dentre outros - o que seriam compartilhados apenas entre os homens e os animais; por fim, a dimensão noética seria aquela pela qual se manifestam todos os fenômenos especificamente humanos, ou seja, que não são compartilhados nem com os animais nem com os vegetais.
Esses fenômenos seriam aqueles tais como: preocupação com valores (éticos, estéticos e religiosos); todo ato de intencionalidade, atividades artísticas e criativa, o senso de humor, bem como a consciência valorativa (Lukas, 1989).

Como o ser humano é o único ser que tem a consciência de sua própria finitude, isso o diferencia de outros entes, conferindo uma estrutura existencial demarcada pela angústia. Na sequência será apresentada a visão de Frankl acerca da morte e da finitude.

\section{A concepção da finitude segundo Frankl}

Segundo Frankl (1989), independentemente da duração de uma existência, ela possui um sentido, e o ser humano passa a buscar um significado ao se deparar com a transitoriedade de sua vida. Para esse autor, a morte e o morrer não seriam algo que destituiria a vida de um sentido, pois o caráter transitório da vida é que impulsiona o ser humano a buscar um sentido para realizar determinada tarefa. Em outras palavras, a finitude dá um sentido para a vida, despertando no ser humano o senso de responsabilidade, visto que a morte faz com que a vida seja única e impossível de ser revertida (Frankl, 1994).

Nessa perspectiva, a existência humana é ser-responsável, em que a responsabilidade origina-se no caráter concreto da pessoa e da situação. Desse modo, o desenvolvimento da responsabilidade humana acompanha o "caráter único" do sujeito e a "irrepetibilidade da situação". Assim sendo, o "caráter único" e a "irrepetibilidade da situação" são elementos constitutivos do sentido da vida humana e conjeturam a finitude humana, ao passo que essa finitude representa algo que dê sentido à existência. Não é cabível, portanto, separar a morte da vida, visto que a morte faz parte dela (Frankl, 1989). 
Destarte, a morte também pode evocar a pergunta pelo sentido da vida (Frankl, 1990), posto que a transitoriedade da existência humana poderia destituir a vida de um sentido ou de um "para que viver". A eternidade é entendida por Frankl (1990) como uma realidade simultânea que compreende o presente, o passado e o futuro. Assim sendo, a finitude, a temporalidade, não é apenas uma nota essencial da vida humana, mas trata-se também daquilo que constitui o seu sentido, posto que no momento em que as potencialidades são realizadas, estas são transferidas do não ser para o ser, das possibilidades para a realidade do passado. Desse modo, o sentido da existência humana funda-se no seu caráter irreversível (Frankl, 1994; 1989).

A logoterapia concebe que o futuro "não é", o passado é a pura realidade, posto que o tempo seria irreversível. Dessa forma, cada instante da vida está também morrendo, pois os instantes são transitórios. Essa transitoriedade dos momentos torna um incentivo para que o ser humano procure realizar ações responsáveis (Frankl, 1994). Tudo o que foi realizado continua a existir posto que passa a fazer parte do passado e permanece como parte da realidade. Portanto, o que foi vivido ninguém pode destruir, torna-se passado e realidade (Frankl, 1990). Nessa perspectiva, Frankl se aproxima de Heidegger (1989) quando este último compreende que "a pré-sença 'é' o seu passado no modo de seu ser, o que significa, a grosso modo, que ela sempre 'acontece' a partir do seu futuro" (p. 48).

No que se refere à transitoriedade da vida, Frankl (1990) afirma que isso realmente só se aplica com relação às possibilidades de dar um sentido às oportunidades de criar, de experienciar, de sofrer com sentido pleno. Nesse sentido, na medida em que o ser humano responde à vida, torna-se responsável por algo. Portanto, a responsabilidade humana encontra-se no "otimismo do futuro", nas escolhas e possibilidades do futuro e no "otimismo do passado", ou seja, transforma as possibilidades em realidade, abrigando-as no passado, visto que tudo é efêmero, porque passa da nulidade do futuro para o passado, no qual tudo vai percorrendo do futuro para o passado, do vazio do futuro para a existência do passado.

O que acontece com a morte é o fato de que tudo o que se vivenciou fixa-se no ser passado e nada mais será modificado, perdendo-se as possibilidades do vir a ser. É nesse sentido que se entende o passado do homem como o seu verdadeiro futuro, como a dimensão mais segura do ser, visto que nada mais daquilo poderá ser eliminado ou modificado (Frankl, 1990).

Desse modo, o ser humano vai se construindo e se modelando, em alguns momentos experienciando vivências, em outros momentos sofrendo. Portanto, o homem deve seguir sua vida no tempo apesar da sua finitude, que delimita o seu projeto existencial (Frankl, 1989; Heidegger, 1990). Tendo em vista as considerações supracitadas, o presente estudo teve como objetivo identificar as concepções da morte e suas repercussões para o sentido da vida entre os adolescentes de uma escola pública da cidade de João Pessoa (PB).

\section{Método}

O estudo partiu da perspectiva da pesquisaação, que, segundo Franco (2005), constitui-se como um instrumento tanto pedagógico como científico. Segundo essa mesma autora, como práxis investigativa, essa metodologia busca conhecer "as perspectivas latentes, o oculto, o não familiar que sustentam as práticas, sendo as mudanças negociadas e geridas no coletivo" (p. 486). Já Tripp (2005) considera que, de forma geral, essa metodologia oscila entre a prática interventiva e a investigação 
como um meio de avaliar os resultados da ação proposta.

\section{Participantes}

Os participantes foram estudantes de uma escola pública da cidade de João Pessoa. Ao todo, contou-se com 17 estudantes do terceiro ano do ensino médio, a maioria do sexo feminino (52,9\%), com idade média de 17 anos e amplitude de 15 a 24 anos.

\section{Procedimentos para a coleta de dados}

Inicialmente, foi solicitada à coordenadora pedagógica da escola a realização de uma intervenção com alunos do ensino médio. Após a sua autorização e por sugestão dela, foi indicada a turma do professor de filosofia dessa escola para que pudesse disponibilizar as suas aulas para a efetivação do projeto. Após a permissão final do professor, foram realizadas cinco intervenções, sendo uma vez por semana, com o tempo médio de 45 minutos. As etapas da intervenção são descritas a seguir:

Primeira intervenção: buscou compreender como os adolescentes do ensino médio percebem ou conceituam o fenômeno "morte". Foi apresentado um vídeo com o tema "Vivendo a vida Sem Drogas" e um questionário com a seguinte pergunta " $\mathrm{O}$ que lhe vem à mente quando você ouve a palavra morte?".

Segunda Intervenção: procurou apreender o conceito acerca do que é o sentido da vida. Também inquiriu se a morte retiraria o sentido da vida.

Terceira intervenção: utilizou-se a história oriental "Morte em Teerã" para refletir sobre a inevitabilidade da morte. Em seguida, perguntou-se "Como seria a vida se não existisse a morte?"
Quarta intervenção: utilizou-se da letra da música de Maria Gadu, "Dona Cila", para evocar as perdas vivenciadas pelos adolescentes. Após a apresentação da música, os adolescentes foram solicitados a expressarem as suas compreensões acerca da letra. Adotou-se uma postura fenomenológica existencial para compreender como os adolescentes percebem a dialética vidamorte.

Quinta intervenção: objetivou saber que relação de valor e sentido esse aluno atribui a sua vida e quais os motivadores, a fim de criar um eixo teórico acerca do sentido da vida. Para essa intervenção, foi preparado um slide com a imagem de um relógio contendo a seguinte frase: "Imagine que o relógio da sua vida vai parar no próximo minuto...". Em seguida, foi solicitado aos participantes que respondessem às seguintes perguntas (1) Quais os fatos mais valiosos da sua vida? (2) O que lamentaria não ter mais tempo de fazer? Essas perguntas foram extraídas do livro Histórias que Curam porque dão sentido à vida, de Elisabeth Lukas (2005). Para finalizar, perguntou-se aos participantes: "O que lhe vem à mente quando você escuta a palavra morte?".

Os dados provenientes da observação dos pesquisadores foram registrados em um diário de campo, enquanto que aqueles provenientes das perguntas eliciadoras foram registrados em folha de papel A4 pelos próprios participantes. Em seguida, todas as respostas dos participantes foram transcritas para um arquivo do Word para fins de análise dos seus conteúdos.

Procedimentos para a análise dos dados

Os conteúdos foram analisados por meio da técnica de Análise de Conteúdo (AC), seguindo os procedimentos sugeridos por Bardin (1977). Dessa forma, inicialmente, realizou-se uma leitura flutuante com a 
intenção de averiguar possíveis agrupamentos. Em seguida, por meio de semelhanças e aproximações, as respostas foram classificadas em categorias, em função de suas características comuns. Para tanto, considerou-se que as categorias não eram excludentes, ou seja, que uma mesma resposta poderia estar contida em mais de uma categoria. Por fim, as respostas foram tabuladas em termos de frequências em função de suas categorias e subcategorias.

\section{Resultados e discussão}

Os resultados que se seguem referem-se às intervenções realizadas junto a adolescentes de uma escola pública. A Tabela 1 apresenta o resultado do significado da morte obtido por meio de uma associação livre em dois momentos: na primeira sessão da intervenção e no término da intervenção.

Tabela 1. Categorias, subcategorias e frequência de respostas dos adolescentes, nas duas etapas da intervenção (início e término), para a questão "O que lhe vem à mente quando você escuta a palavra morte?"

\begin{tabular}{|c|c|c|c|}
\hline \multicolumn{4}{|c|}{ Frequência das respostas } \\
\hline \multicolumn{2}{|c|}{ Categorias e subcategorias: } & da intervenção & Termino da intervenção \\
\hline & & $(n=16)$ & $(n=17)$ \\
\hline \multirow[t]{4}{*}{ Sentimentos } & Tristeza & 3 & 4 \\
\hline & Angústia & 1 & 2 \\
\hline & Medo & 1 & 2 \\
\hline & Vazio & 1 & - \\
\hline \multirow[t]{3}{*}{ Crenças } & Separação & 4 & 1 \\
\hline & Sono profundo & 1 & - \\
\hline & Julgamento & -1 & \\
\hline \multirow[t]{5}{*}{ Pensamentos } & Violência & 2 & 1 \\
\hline & Lembrança de pessoas & 2 & - \\
\hline & Pensamento concreto & 2 & - \\
\hline & Fim & 2 & 5 \\
\hline & Desconhecido & - & 2 \\
\hline
\end{tabular}

Na primeira categoria apresentada na Tabela 1, agrupam-se os sentimentos em relação à morte. As subcategorias que a compõe foram: tristeza, angústia, medo e vazio. Alguns exemplos dessa categoria são destacados a seguir:

O que vem na minha mente é tristeza, dor, sentimento de perda daquela pessoa que sempre teve ao meu lado e de repente morre [...] (17 anos, sexo feminino); Vem um pouco de angústia, eu me sinto mal na verdade eu não sei lidar com isso [...] (17 anos, sexo feminino); Em minha mente vem certo tipo de medo, eu tenho um pouco de medo da morte [...] (15 anos, sexo masculino); A primeira coisa que vem a minha mente quando eu escuto a palavra morte é uma coisa bem vazia você deixa de ser um ser vivo e passa a ser um ser morto [...] (17 anos, sexo feminino).

Esses relatos corroboram com o estudo de Rodriguez (2005), que buscou compreender como os adolescentes percebem o tema da morte. Encontrou-se no discurso dos participantes o sentimento de tristeza em relação a perdas de entes queridos. Um estudo realizado com 42 pré-adolescentes 
Já Heidegger (1990) esclarece que a angústia com a morte não deve ser confundida com o temor de deixar de viver, posto que a disposição fundamental do ser-no-mundo é o estar lançado para o seu fim. portugueses constatou que a discussão acerca da morte causa desconforto, sobretudo por evocar sentimentos negativos (De Macedo, Macedo \& Gomes, 2010). O estudo de Dal Mas Dias (2011), que objetivou identificar a representação da morte em sete adolescentes por via da produção literária, identificou que o tema provocou angústia existencial. A autora também considera que "a escola tem a função de abrir-se à discussão sobre a morte e a finitude, alargando os domínios restritos à sistematização do conhecimento" (p. 280). Já Heidegger (1990) esclarece que a angústia com a morte não deve ser confundida com o temor de deixar de viver, posto que a disposição fundamental do ser-no-mundo é o estar lançado para o seu fim. Dessa forma, para esse filósofo, o adiantar-se à morte abre para a questão do ser.

A segunda categoria foi denominada de crenças, pois se constitui de representações simbólicas sobre a morte: Separação, Sono Profundo e Julgamento. Como exemplos destacam-se as seguintes respostas:

[...] Creio que quando morremos neste momento haverá a separação do nosso corpo carnal [...] (17 anos, sexo feminino); Quando paro para pensar na morte eu penso em um sono profundo aonde aqueles que se vão estão apenas dormindo [...] (18 anos, sexo masculino); [...] eu penso em um sono profundo aonde aqueles que se vão estão apenas dormindo aguardando o julgamento de Deus [...] (18 anos, sexo masculino).

Os sistemas de crenças religiosas foram ativados para explicar o fenômeno da morte. De forma geral, as crenças religiosas apresentam-se associadas às concepções positivas da morte e do morrer, como pode ser constatado por meio do estudo de Diniz e Aquino (2009). Assim, em um contexto de estudantes universitários, quando indicam que o nível de religiosidade dos estudantes universitários está associado positivamente com a visão de morte como vida do além, coragem e fim natural, e negativamente com a visão de fracasso.
Por fim, a terceira categoria, Pensamentos, agrupou respostas relacionadas à violência, lembranças de pessoas, pensamento concreto, fim e desconhecido. Essas subcategorias são apresentadas a seguir:

[...] é a palavra violência, [...] Hoje o jovem não morre por causa de doença a maioria morre por causa de violência [...] (sexo feminino, 18 anos); [...] Vem à mente alguém que se foi e jamais podemos vê-lo novamente (sexo feminino, 17 anos) [...]; [...] vem vários símbolos à mente como: caixão, cemitério, velas, ou seja, coisas que se usam em pessoas que passaram por ela [...] (sexo feminino, 17 anos); geralmente eu penso que é o fim, pois neste mundo temos apenas uma vida [...] (sexo masculino, 17 anos); [...] Eu não sei o que irá vir depois da morte, contudo, sei que a morte não é o fim de tudo ou da vida [...] (sexo masculino, 17 anos).

Constata-se que os adolescentes investigados apresentam contato com a morte e o morrer, seja de entes queridos ou mesmo de colegas da sua faixa etária. De acordo com Paiva et al. (2009), a violência é a maior causa da mortalidade entre os jovens de 15 a 29 anos, sendo considerado esse período como de alto risco. Dessa forma, segundo Kovács (2011), ao mesmo tempo em que a morte é um interdito, está também próxima das crianças e dos adolescentes.

De forma geral, quando se compara a representação da morte, em função do início e do fim da intervenção, constata-se que os aprendizes permanecem com os mesmos sentimentos, entretanto, tais crenças vão se dissipando, enquanto alguns pensamentos aparecem de forma mais elaborada. Segundo Beck (1976), o sistema de crenças de um indivíduo está diretamente associado aos seus sentimentos e comportamentos. Destarte, os debates sobre a morte e o morrer junto aos estudantes dessa pesquisa, por um lado despertaram sentimentos como tristeza, por outro, puderam proporcionar a construção de novos pensamentos catalisadores que ajudaram a incorporar a finitude como um dos elementos que fazem parte da estrutura ontológica do ser humano. 
Tabela 2. Categorias, subcategorias e frequências para a questão: "Qual o sentido da vida?" (n $=17$ )

\begin{tabular}{llc}
\hline Categorias e subcategorias & & Frequência \\
\hline Sentido Subjetivo & Felicidade & 3 \\
& Prazer & 1 \\
& Alegria & 2 \\
& Bem-estar & 1 \\
& Paz & 2 \\
Sentido Objetivo & Aproveitar a vida & 1 \\
& Deus & 8 \\
& Pessoas & 2 \\
& Família & 5 \\
& Alcançar objetivos & 2 \\
& O bem & 2 \\
\hline
\end{tabular}

A concepção do sentido subjetivo está em consonância com a visão hedônica, que de forma geral pressupõe o bem-estar como felicidade (Ryan, Huta \& Deci, 2008). Já a concepção do sentido como algo objetivo está relacionado à concepção de Frankl $(1989,1990,1991)$ como autotranscendência. Para esse autor, o ser humano deve estar direcionado a algo ou a alguém distinto de si mesmo e na medida em que está dedicado a uma causa ou pessoa, mais humano e saudável será. Para Frankl (1990), a felicidade e o prazer seriam uma consequência da realização de um sentido concreto e objetivo no mundo.

A compreensão ontológica dos adolescentes apresentou semelhanças com o pensamento de Frankl quando os mesmos apontam os valores como meios para alcançar o sentido da vida, sobretudo os vivenciais como: Deus, pessoas e família. Não obstante, as concepções hedonistas ainda permeiam o imaginário dos adolescentes quando indagados sobre o sentido da vida. Esse resultado pode ser compreendido mediante a influência da cultura de consumo e narcisista em que os jovens estão inseridos.

Tabela 3. Categorias e subcategorias para a questão: "Imagine que o relógio da sua vida vai parar no próximo minuto..."

\begin{tabular}{llcc}
\hline Categoria & Subcategoria & Fatos mais valiosos da vida & $\begin{array}{c}\text { O que lamentaria não ter } \\
\text { mais tempo para realizar }\end{array}$ \\
\hline \multirow{2}{*}{ Vivenciais } & Família & Frequência & Frequência \\
\cline { 2 - 3 } & Amigos & 7 & 6 \\
& Transcendência & 7 & 1 \\
& Namoro & 1 & 2 \\
& Natureza & 2 & - \\
& Arte & - & 1 \\
& Esporte & - & 2 \\
Atitudinais & Decepções & - & 1 \\
& Tristezas & 1 & - \\
& Crescimento & 1 & - \\
& Assumir culpa & 2 & - \\
Criativos & Faculdade/Profissão & - & 7 \\
& Realizar objetivos/sonhos & - & 3 \\
Não categorizável & - & 1 \\
Nand livro & 2 & 1 \\
\hline
\end{tabular}


Conforme a logoterapia e a análise existencial, a preocupação com os valores são consequência da tomada de consciência da finitude humana, visto que, ao se deparar com a certeza de sua morte, o homem preocupa-se com a realização de valores, a fim de encontrar um sentido na vida. Frankl (1988) expressa a relação entre valores e finitude da seguinte maneira:

por definición, el analisis existencial apunta a una tomada de consciencia de asumir responsabilidades. Pero la responsabilidad la tiene el hombre frente a su finitud. La finitud del hombre, sin embargo, está dada, ante todo, en lo temporal de su existência y nos enfrenta em primera línea como mortalidad. Pero de ella sabemos que es justamente la que da valor a la responsabilidad del hombre ya que si este fuera inmortal, con todo el derecho podría dejar pasar las oportunidades de realizar valores (pp. $102-103)$

Nesse sentido, como pode ser observado na Tabela 3, na categoria dos valores vivenciais refletidos pelos jovens, ao se depararem com a finitude de suas vidas, demonstrou-se como fator mais valioso e que mais seria lamentado por não ser realizado, o fator família, além do fator amigos, que apareceu como um dos fatores mais valiosos na vida dos jovens.

Assim, segundo Frankl (1989), os valores vivenciais são aqueles que são via de sentido ao homem receber algo do mundo, por meio de vivências. Dessa forma, a família e as amizades estariam envolvidas nessas vivências que trazem sentido à existência desses jovens, assim como seriam valores lamentados por não serem realizados com a morte, pois o jovem deseja constituir família em seu futuro e realizar experiências afetuosas.

Com relação aos valores atitudinais, o fator crescimento obteve maior frequência nos jovens, como o valor mais valioso de suas vidas, assim como o valor assumir culpa que obteve maior frequência como o valor que seria mais lamentado ao não ser realizado por meio da morte. Dessa forma, esses dados mostram correspondência ao que Frankl (1989) discutiu acerca dos valores atitudinais, sendo esses valores relacionados à possibilidade do ser humano posicionar-se perante uma situação inevitável, como uma situação de sofrimento. Com isso, o crescimento e a capacidade de assumir culpa são valores que demonstram uma possibilidade do homem se posicionar perante uma situação imutável e ao sofrimento que ela pode causar, sendo então reflexo da liberdade última do homem de se posicionar frente a uma situação, causando a realização de sentido.

Por fim, a categoria dos valores criativos demonstrou os valores de faculdade/profissão e realizar objetivos e sonhos como os valores que seriam mais lamentados por não serem realizados por consequência da morte. Os valores criativos estão relacionados com atos de criação em que o homem constrói algo para o mundo, por meio do trabalho, estudos, obras artísticas etc. (Frankl, 1989).

Portanto, o fato de que os valores referentes à realização de objetivos e sonhos e de fazer faculdade e profissão são apontados pelos jovens como valores que trariam lamentação por não serem realizados perante a morte, pode estar relacionado com o fato de que os jovens estudantes encontram sentido nos seus estudos ao buscarem uma estabilidade profissional no futuro, ou a entrada na faculdade, por exemplo. Portanto, a morte acarretaria a não possibilidade da realização de metas e objetivos desses jovens, trazendo então a lamentação pela não realização desse valor. Segundo Heidegger (1990), a antecipação da possibilidade da morte leva o ente a compreender o seu poder-ser. Conforme pensa esse autor, "a antecipação da possibilidade irremissível obriga o ente que assim antecipa à possibilidade de assumir seu próprio ser a partir de si mesmo e para si mesmo" (p. 47).

Para finalizar, no que refere à pergunta "Como seria a vida se ninguém morresse?", observaram-se as seguintes respostas: 
Resposta 1. O mundo ficaria superlotado; as pessoas não dariam valor à vida se não tivessem medo de perdê-la. Dependendo da visão que se tem sobre a morte, ela não existir seria um problema...

Observa-se que esse tipo de argumento apresenta certo pragmatismo que leva a uma representação objetiva da morte. Por um lado, aponta que o medo da morte, a possibilidade do não-ser, levaria a pessoa a valorar a própria existência e por outro, a morte previne a superlotação do mundo.

Resposta 2. A princípio, penso que teríamos chance de "voltar atrás" em algumas coisas e corrigir erros, mas não tendo fim, não teríamos ideia do quanto queríamos buscar novas coisas ou ter novas experiências, e até que ponto existiriam novas experiências? A que a vida é uma repetição de atitudes e fatos.

O argumento de ter uma nova chance para corrigir erros passados não está condicionado com a imortalidade, já que nas possibilidades futuras o ser humano pode vir a remediar seus atos, embora a morte retire a área de liberdade do ser humano (Frankl, 1989). Assim, Frankl (1989) compreende que, se os homens tivessem uma vida infinita, adiariam frequentemente suas escolhas e não possuiriam assim um sentido para realizarem os valores que vivessem no momento.

Resposta 3. Qualquer coisa é melhor que a morte. Uma delas é viver eternamente.

Esse tipo de argumento refere-se a uma postura religiosa da morte, a qual concebe que a mortalidade leva a imortalidade da "alma", posto que o homem religioso vive em função de uma vida eterna. Não obstante, segundo a análise existencial de Frankl (1989), com a morte, o ser humano sai da condição da temporalidade, restando apenas a dimensão do ser-passado, o que se constitui em sua perenidade.

Resposta 4. Seria infinita ( $\infty)$.
Outro tipo de resposta foi de cunho tautológico, ou seja, apresenta uma repetição contida na própria pergunta. Isso pode ser interpretado como uma forma de evitar uma reflexão sobre a condição da finitude da existência humana, já que o refletir sobre a morte elicia sentimentos de angustia e medo.

Resposta 5. Não existiria vida se não tivesse morte, pois nada dura para sempre. Qual o sentido da vida se não houver a morte? A morte faz com que nos agarremos a vida, para nos fazer pensar o quanto ela é valiosa. A morte na nossa vida nos faz admirar, gostar, amar pessoas ou algo antes que a morte chegue.

Por fim, esse tipo de resposta revela um grau de elaboração diferente das anteriores por integrar a morte com a própria vida em uma perspectiva dialética. A morte nesse aspecto seria o principal motivador dos atos especificamente humanos como o amor, além disso, vincula a existência humana à vida, sobretudo aos valores vivenciais, o que, por conseguinte, valorizaria a própria existência. O próprio Frankl (1994) aventou que a transitoriedade deve ser um incentivo para realizar as ações responsáveis na existência humana.

\section{Considerações finais}

O objetivo do presente estudo foi identificar as concepções da morte e suas repercussões para o sentido da vida entre estudantes do ensino médio. Considera-se que o escopo do artigo foi atingido, tendo em vista que foram mapeados os principais conceitos sobre a morte e averiguada a sua relação com o sentido da vida. Foi possível constatar que os adolescentes ainda se esquivam das discussões acerca da morte e do morrer, posto que para os dias atuais os temas relacionados com a finitude ainda se constituem como um tabu. Entretanto, na autoavaliação dos participantes, a morte está vinculada com a própria vida, como pode ser observado no 
relato de um dos participantes: Nunca penso na morte. Esse foi um jeito de me fazer pensar na minha própria vida.

Frankl (2003) considerou que a educação pode ter um papel preponderante no que se refere ao refinamento da consciência dos jovens para a descoberta do sentido e dos valores que estão enraizados na existência. Dessa forma, o debate sobre a morte em um ambiente escolar fez com que os participantes pudessem expressar livremente suas crenças e concepções acerca da finitude, bem como proporcionou uma reflexão sobre os valores que os guiam, tornando-os consciente dos significados que permeiam suas vidas. Segundo pensa Frankl
(1994), a transitoriedade tem uma importante função para a existência humana, qual seja, "constitui a nossa responsabilidade, porque tudo depende de nos conscientizarmos das possibilidades essencialmente transitórias" (p. 106).

Assim, constatou-se que as discussões sobre a morte promoveram uma reflexão sobre a vida, integrando a dualidade vida-morte. A partir dos resultados desse estudo, sugere-se que os componentes curriculares possam abrir um espaço para discussões que angustiam a vida dos estudantes, no intuito de expressar temas do cotidiano que estão imbricados com a existência desses jovens.

\section{Thiago Antonio Avellar de Aquino}

Doutor em Psicologia Social pela Universidade Federal da Paraíba (UFPB). Docente do departamento de Ciências das religiões da Universidade Federal da Paraíba, João Pessoa - PB - Brasil.

E-mail: logosvitae@ig.com.br

Andrei Alves de Aguiar

Mestre em Ciências das Religiões pela Universidade Federal da Paraíba e doutorando em Psicologia Social na Universidade Federal da Paraíba, João Pessoa - PB - Brasil.

E-mail: andreipsicologia@hotmail.com

\section{Sarah Xavier Peixoto de Vasconcelos}

Graduada em Psicologia pela Universidade Federal da Paraíba e psicóloga residente do Instituto de Medicina Integral Professor Fernando Figueira - IMIP, Recife - PE - Brasil."

E-mail: sarah_xpv20@hotmail.com

\section{Sergio Lopes dos Santos}

Discente do curso de Ciências das Religiões da Universidade Federal da Paraíba, João Pessoa - PB - Brasil.

E-mail: sergiolopsantos@gmail.com

Endereço para envio de correspondência:

Rua Mário Batista Júnior, n. 75, apt. 301, Miramar. CEP: 58043-130. João Pessoa, PB.

Recebido 31/01/2012, Aprovado 29/08/2013. 


\section{Referências}

Adler, A. (1998). What Life Should Mean to You. Minnesota: Hazelden (Trabalho original publicado em 1931).

Aquino, T. A. A.; Serafim, T. D. B.; da Silva, H. D. M; Barbosa, E. L.; Cirne, A. A.; Ferreira, F. R. \& Dantas, P. R. S. (2010). Visões de morte, ansiedade e sentido de vida: um estudo correlacional. Psicologia Argumento, 28(63), 289-302.

Ariés, P. (1977). A história da morte no Ocidente. Rio de janeiro: Francisco Alves.

Bardin, L. (1977). Análise de conteúdo. Lisboa: Edições 70.

Beck. A. T. (1976). Cognitive Therapy and Emotional Disorders. New York: New American Library.

Dal Mas Dias, E. T. (2011). Adolescência e morte: Representações e significados. Psicologia Escolar e Educacional, 15(2), 273- 281. doi: http://dx.doi.org/10.1590/S1413-85572011000200009

De Macedo, F. D. C., Macedo, J. C. G., \& Gomes, M. F. P. (2010). Educar para a morte e a promoção da saúde mental. Revista portuguesa de enfermagem de saúde mental, 3, 48-53. Recuperado de http://hdl.handle.net/1822/10920

Diniz, A. C., \& Aquino, T. A. A. (2009). A relação da religiosidade com as visões de morte. Religare, 6(2), 101-113.

Donovan J. M. (1993).Validation of a portugueses form of Templer's death anxiety scale. Psychological reports, 73, 195-200.

Epicuro (1994). Obras. Estudio preliminar (M. Jufresa, Trad.). Madrid: Editorial Tecnos.

Franco, M. A. S. (2005). Pedagogia da pesquis-ação. Educação e Pesquisa, 31(3), 483 - 502. doi: http://dx.doi.org/10.1590/ S1517-97022005000300011

Frankl, V. E. (1988). La vontad de sentido. Barcelona: Editorial Herder

Frankl, V. E. (1989). Psicoterapia e sentido da vida (A. M. Castro, Trad.). São Paulo: Quadrante. (Trabalho original publicado em 1946).

Frankl, V. E. (1990). Logoterapia y análisis existencial: Textos de cinco décadas. (J. A. de Prado Diez; R. Wenzel\& I. Arias, Trads.). Barcelona: Editorial Herder.

Frankl, V. E. (1991). A psicoterapia na prática (C. M. Caon, Trad.). Campinas, SP: Papirus.

Frankl, V. E. (1994). Em busca de sentido: Um psicólogo no campo de concentração. (H. H Reinhold, Trad.). Petrópolis, RJ: Vozes.

Frankl, V. E. (2003). A presença ignorada de Deus. São Leopoldo, RS: Editora Sinodal

Freud, S. (1976). Novas conferências introdutórias sobre Psicanálise. In S. Freud, Edição standard brasileira das obras psicológicas completas de Sigmund Freud (J. Salomão, Trad., Vol. 22, pp. 17-220). Rio de Janeiro: Imago. (Trabalho original publicado em 1933)
Trad.). Petrópolis, RJ: Vozes.

Heidegger, M. (1990). Ser e Tempo (parte II). (M. de Sá Cavalcanti, Trad.). Petrópolis, RJ: Vozes.

Kovács, M. J. (1992). Morte e desenvolvimento humano. São Paulo: Casa do Psicólogo.

Kovács, J. (2005). Educação para a morte. Psicologia Ciência e Profissão, 25(3), 484-497. doi: http://dx.doi.org/10.1590/ S1414-98932005000300012

Kovács, J. (2011). Instituições de saúde e a morte. Do interdito à comunicação. Psicologia Ciência e Profissão, 31(3), 482-503. doi: http://dx.doi.org/10.1590/S1414-98932011000300005

Lukas, E. (1989). Logoterapia, "a força desafiadora do espírito": Métodos de logoterapia. São Paulo: Loyola.

Lukas, E. (2005). Histórias que curam porque dão sentido à vida, (C. A. Pereira, Trad.). Campinas, SP: Editora Verus.

Mondin, B. (2005). Os valores fundamentais (J. T. Garcia, Trad.). Bauru, SP: Edusc

Nietzsche, F. (1996) Obras Incompletas. São Paulo: Nova Cultural.

Nogueira, D., \& Pereira, L. (2006). Perspectivas da morte de acordo com a religiosidade: Estudo comparativo. Recuperado de http://www.psicologia.pt/artigos/textos/TL0058.pdf.

Paiva, A. B.; Ribeiro, J.A.; Silva, J. R., Servo, L. M. S., Nogueira, R. P., \& Piola, S. F. (2009). Jovens: morbimortalidade, fatores de risco e políticas de saúde. In J. A. de Castro, \& L. M. C. de Aquino (Orgs), Juventude e políticas sociais no Brasil, (pp. 131-147), Brasília, DF: IPEA.

Patraglia, I \& Bastos, C. R. F. (2009). Mote, complexidade e educação. Notandum Libro, 13, 21-28

Spilka, B., Stout, L., Minton, B., \& Sizemore, D. (1977). Death and personal faith: A psychometric investigation. Journal for the Scientific Study of Religion, 16(2), 169-178.

Ryan, R. M., Huta, V., \& Deci, E. L. (2008). Living well: A selfdetermination theory perspective on eudaimonia. Journal of happiness studies, 9, 139-170. doi: 10.1007/s10902006-9023-4

Rodriguez, C. F. (2005). O que os jovens têm a dizer sobre a adolescência e o tema da morte. Dissertação de Mestrado, Instituto de Psicologia da Universidade de São Paulo: São Paulo.

Schopenhauer, A. (2000). Metafísica do amor metafísica da morte, (J. Barboza, Trad.). São Paulo: Martins Fontes.

Tripp. D. (2005). Pesquisação: uma introdução metodológica. Educação e pesquisa, 31(3), 443-466. doi: http//dx.doi. org/10.1590/S1517-97022005000300009

Xausa, I. A. de M. (2003). O sentido dos sonhos na psicoterapia em Viktor Frankl. São Paulo: Casa do Psicólogo. 